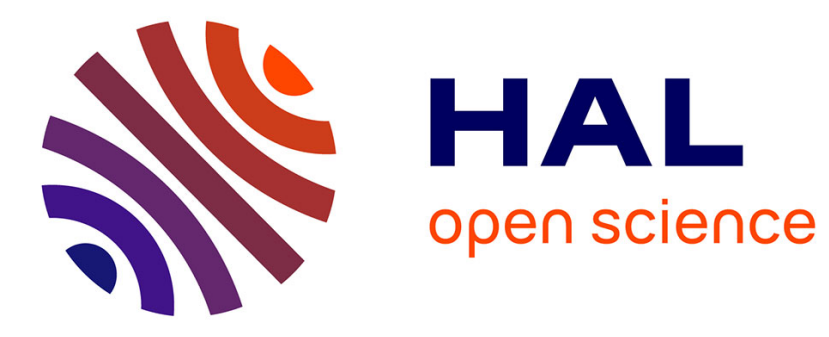

\title{
Dynamic hybrid reliability studies of a decay heat removal system
}

Ranjan Kumar, Sevostian Bechta, Pavel Kudinov, Florence Curnier, Michel Marques

\section{- To cite this version:}

Ranjan Kumar, Sevostian Bechta, Pavel Kudinov, Florence Curnier, Michel Marques. Dynamic hybrid reliability studies of a decay heat removal system. International Journal of Reliability, Quality and Safety Engineering, 2015, 22 (04), pp.1550020. 10.1142/S0218539315500205 . cea-02385765

\section{HAL Id: cea-02385765 https://hal-cea.archives-ouvertes.fr/cea-02385765}

Submitted on 29 Nov 2019

HAL is a multi-disciplinary open access archive for the deposit and dissemination of scientific research documents, whether they are published or not. The documents may come from teaching and research institutions in France or abroad, or from public or private research centers.
L'archive ouverte pluridisciplinaire HAL, est destinée au dépôt et à la diffusion de documents scientifiques de niveau recherche, publiés ou non, émanant des établissements d'enseignement et de recherche français ou étrangers, des laboratoires publics ou privés. 


\title{
DYNAMIC HYBRID RELIABILITY STUDIES OF A DECAY HEAT REMOVAL SYSTEM
}

\author{
RANJAN KUMAR*, SEVOSTIAN BECHTA, PAVEL KUDINOV \\ Nuclear Power Safety, KTH Royal Institute of Technology, SE - 10691 Stockholm, Sweden \\ rankum@kth.se,bechta@kth.se \\ FLORENCE CURNIER, MICHEL MARQUES \\ DEN/CAD/DER/SESI, CEA Cadarache, F-13108 Saint-Paul-lez-Durance, France \\ florence.curnier@cea.fr,michel.marques@cea.fr
}

Abstract

Some critical safety systems exhibit the characteristics of hybrid stochastic class whose performance depends on the dynamic interactions of deterministic variables of physical phenomena and probabilistic variables of system failures. However, conventional probabilistic safety assessment (PSA) method involves static event and linked fault tree analysis and does not capture the dynamic interactions of such hybrid stochastic systems. Additionally, the existing dynamic PSA methods do not considers any repair possibility of some failed components during safety assessment. To address these issues, this paper presents a dynamic hybrid reliability assessment scheme for performance studies of repairable nuclear safety systems during a mission time. This scheme combines the features of reliability block diagram (RBD) for system compositions and partial differential equations for system physics using a customized stochastic hybrid automata tool implemented on Python platform. A case study of decay heat removal (DHR) systems has been performed using the introduced scheme. The impacts of failure rates and repair rates on sodium temperature evolution over a mission time have been analyzed. The results provide useful safety insights in mission safety tests of DHR systems. In sum, this work advances the dynamic safety assessment approach for complex system designs including nuclear power plants.

Keywords: Probabilistic safety assessment; dynamic reliability; decay heat removal system; stochastic hybrid automata; piecewise deterministic Markov process 


\section{Introduction}

The design of advanced nuclear safety systems, such as decay heat removal (DHR) systems are increasingly utilizing passive systems in addition to active ones to enhance the overall safety of nuclear power plants ${ }^{1,2}$. As classified by IAEA-TECDOC-626, the category B safety systems such as reactor shutdown/emergency cooling systems, containment cooling systems, fluidic gates between process systems, etc. are well known passive systems ${ }^{3}$. Although passive safety systems do not require any external input to operate, they often interact with physical processes such as thermal-hydraulic phenomena, flow of working fluids, etc. Therefore, such systems are prone to random failure due to mechanical and electrical parts and deterministic failure due to crossing the physical limits. Mathematically, the systems which involve continuous and discrete variables and subject to random process are termed hybrid stochastic systems ${ }^{4,5}$. The reliability evaluation of hybrid stochastic system (HSS) during a mission time is considered to be a complex $\operatorname{task}^{6}$ of nuclear safety studies.

Conventionally, probabilistic safety assessment (PSA) methodology is applied for reliability studies of nuclear safety systems ${ }^{7}$. In practice, PSA level-1 is applied to assess the reliability of nuclear safety systems in terms of core damage frequencies (CDF) during both design and operation stages. The PSA level-1 method identifies initiating events (IE), generates accident sequences for each IE, and estimates consequence probabilities using the linked fault tree analysis of safety barriers. However, PSA level-1 studies are "static" in nature and do not take into account the dynamic states of the system. To overcome this issue, several works on "dynamic" methodologies for PSA of nuclear plants have been introduced in literature ${ }^{8}$. These dynamic PSA methodologies can be divided into three main categories: continuous time methods, discrete time 
methods, graphical interface methods. The inputs of all dynamic methodologies are a time-dependent system model ( (uch as RELAP5 ${ }^{9}$, MELCOR $^{10}$ ), possible normal and abnormal system configurations, and transitions probabilities among these configurations.

Most of these dynamic PSA methods have been categorized under discrete dynamic event tree (DDET) as computational engines of dynamic reliability methods [6]. These are more focused on generating time-dependent event tree dynamically such as $\operatorname{DYLAM}^{11}, \operatorname{DETAM}^{12}, \mathrm{ADS}^{13}, \mathrm{MCDET}^{14}, \mathrm{ADAPT}^{15}$, and the others. As opposed to typical dynamic reliability models, DDET methods do not take into account the real-time interaction between continuous physical processes and discrete events explicitly. Furthermore, none of the dynamic PSA methods described in Ref.8 take into account multiple initiating events, the possibility of repair of some failed parts during state transitions, functional dependencies and cascading behaviors, etc., in system modeling whereas needed to assess the safety of hybrid systems.

Nevertheless, the aforementioned methodological difficulties of hybrid systems safety assessment can be sorted out using dynamic reliability methods which provide a framework for explicitly capturing the influence of time and process dynamics on scenarios $^{6}$. Dynamic reliability methods are capable of handling interactions among components and process variables explicitly. In principle, they constitute a more realistic modeling of systems for the purposes of safety analysis. Several methods such as Stochastic petri nets $(\mathrm{SPN})^{16}$, Event sequence diagram (ESD) $)^{17}, \mathrm{GO} \mathrm{FLOW}^{18}$, Dynamic Flow Method (DFM $)^{19}$, Boolean logic Driven Markov Process(BDMP) ${ }^{20}$, etc. have been proposed to assess dynamic reliability of complex systems. These methods are generally composed of input representation schemes and solution schemes and thus, do not allow direct coupling of physical behavior. 
The recent works on hybrid stochastic methods demonstrate the capability to include physical equations directly in their modeling and simulations of dynamic reliability ${ }^{21,22}$, 23, 24, 25, and 26 . Most of these dynamic reliability approaches for hybrid stochastic systems are built upon the piecewise deterministic Markov processes (PDMP) ${ }^{27}$. The PDMP allows semi-analytical resolution of the dynamic reliability. The use of hybrid stochastic automata (SHA) in PDMP provides compositional modeling capabilities to deal with large scale systems. The SHAs used in these methods are able to represent continuous and discrete variables and model the system structure and behavior. A Pythonic Object Oriented Hybrid Stochastic Automata (PyCATSHOO) ${ }^{25}$ method provides the compositional modeling potentialities because it has two kinds of SHA, one discrete stochastic automaton for component behavior and the other hybrid stochastic automaton for physical phenomena. So, the compositional capabilities of PyCATSHOO make it a good candidate for modeling of stochastic hybrid behavior of complex nuclear safety systems.

Though compositional modeling of PyCATSHOO has Object Oriented, Multi-Agent Systems and functional programming paradigms, they lack inbuilt reliability block diagram (RBD) and Fault Tree (FT) features to estimate the top event probability of automaton states while selective interactions between physical and random variables. Because in hybrid safety systems, some components interact with deterministic phenomena and are still connected to pure discrete system, i.e. support systems such as ventilation, I\&C, and, electrical supply system, etc. A hybrid reliability model can solve the issue of modeling of inter-dependability of discrete systems and system dynamics ${ }^{28}$. Therefore, this paper attempts to present a dynamic hybrid reliability scheme to combine traditional reliability tools such as RBD and FT with PyCATSHOO. 
Rest of this paper is organized as follows. Section 2 introduces a dynamic hybrid reliability assessment scheme for large scale systems of nuclear safety systems. In this section, a detailed modeling procedure using a hybrid combination of reliability block diagram and PyCATSHOO is described. In Section 3, dynamic reliability studies of decay heat removal (DHR) systems of a sodium fast reactor type are performed. Section 4 presents results and discussion on the performed studies in Section 3. Finally, Section 5 concludes the works of this paper.

\section{Dynamic hybrid reliability assessment approach}

\subsection{Dynamic reliability concept}

The "dynamic reliability" studies the dynamic behavior of hybrid safety systems with random transitions and deterministic evolutions during a mission time. Mathematically, the dynamic reliability model expresses the system's dynamic behavior which is represented by a set of interacting continuous and discrete variables. The deterministic dynamics of continuous variables are formalized by a system of differential equations, and triggered behaviors of discrete variables are the transition states of the system. Probabilistic dynamics can allow interlacement between the dynamic evolution of a system and its random transitions ${ }^{29}$.

Now, let us suppose that the states of a system with $\mathrm{N}$ components are defined by a vector, $i=(i(1), i(2), \ldots, i(N))$ and the vector of the process variables at time $t$ is denoted by $x(t)$. If the system enters a state $i$ at time $t$, the physical evolution of the system in that state is given by following vector equation:

$$
\frac{d x(t)}{d t}=f_{i}(x(t), t), \quad x(t) \in \mathbb{R}^{n}
$$


Its formal solution is

$$
x(t)=g_{i}\left(x_{0}, t\right), \text { where } x_{0} \text { is the initial value }
$$

To quantify deterministic and stochastic behavior jointly, the probability density function $\pi(x(t), i, t)$ of the system to be in state $i$ at time $t$ with physical variable vector $x(t)$ is introduced. Suppose, $\lambda_{i}(x)$ be the total transition rate out of the state $i$ and the $p(j \rightarrow i)$ be the specific transition rate between state $j$ to state $i$, then the probability density $\pi$ obeys the Chapman-Kolmogorov equation under a Markovian hypothesis [29] and given by,

$$
\begin{gathered}
\frac{\partial \pi(i, x, t)}{\partial t}+\operatorname{div}\left(f_{i}(x, t) \pi(i, x, t)\right)+\lambda_{i}(x) \pi(i, x, t)=\sum_{j \neq i} p(j \rightarrow i \mid x) \pi(j, x, i) \\
\lambda_{i}(x)=\sum_{j \neq i} p(j \rightarrow i \mid x)
\end{gathered}
$$

Thus, the dynamic reliability of a system can be expressed by the integral form of Eq.(3) as follow;

$$
\begin{gathered}
\pi(i, x, t)= \\
\int_{x_{0}}^{x} \pi\left(i, x_{0}, 0\right) \delta\left(x-g_{i}\left(t, x_{0}\right)\right) \exp \left[-\int_{0}^{t} \lambda_{i}\left(g_{i}\left(s, x_{0}\right)\right) d s\right] d x+\sum_{j \neq i} \int_{x_{0}}^{x} p(j \rightarrow i \mid x) d x \times \\
\text { ot } \delta(x-g i x, t-\tau) \times \exp [-O t-\tau \lambda i g i s, x d s] \times \pi x, j, \pi d \tau
\end{gathered}
$$

Where $\delta$ is a Dirac function $\delta\left(x-g_{i}\left(t, x_{0}\right)\right)$ representing possible trajectories of physical variables leading to $x$ at time. $\pi\left(i, x_{0}, 0\right)$ is the probability of a system to be in state $i$ at $t=0$ given the values of physical variables $x_{0} \cdot \exp \left[-\int_{0}^{t} \lambda_{i}\left(g_{i}\left(s, x_{0}\right)\right) d s\right]$ is the reliability at time $t$. The first term of Eq.(5) corresponds to probability to be in discrete state $i$ over $(0, \mathrm{t})$ without any transition and integrated over all possible deterministic trajectory given by system dynamics. The second term is made of all transitions from other states $(j \neq i)$ to state $i$ taking place before time $t(\tau<t)$ and integrated over all possible deterministic trajectories and time instants. The transitions in 
second term occur according to the Markovian assumption i.e., without any memory of any prior trajectory.

\subsection{Stochastic Hybrid Automata}

For safety assessment of large scale systems like nuclear safety systems, analytical solution of dynamic reliability model, as explained in Eq. (5), is not workable ${ }^{6}$. The approximation methods such as PDMP and MC simulation with SHA are capable to solve dynamic reliability models of large systems ${ }^{6,8,21,22,23, \& 25}$. Since Pythonic Object Oriented Hybrid Stochastic Automata (PyCATSHOO) method has two kinds of stochastic hybrid automata (SHA), this can be a competent method to deal with dynamic reliability studies of large scale system like nuclear safety systems ${ }^{25}$. A stochastic hybrid automaton can be defined as a 7-tuple: $S H A=(M, X, \operatorname{Inv}, T, f, m, x)$, Where :

- $M$ is a set of discrete states, locations or modes.

- $X \in R^{n}$ is a continuous state space.

- Inv $: M \rightarrow 2^{X}$ is a function that gives, for each modem, $m \in$ $M, \operatorname{Inv}(m) \subseteq X$, a subset of the continuous state space which represents the invariant condition of the mode $m$.

- $T$ is the set of random transitions.

- $f: M \rightarrow f_{m}: X \rightarrow X$ characterizes the continuous dynamics for every mode.

$m \in M$ is an initial discrete state (initial mode) and $x_{0}$, an initial continuous state.

\subsection{Hybrid reliability assessment approach}

The nuclear safety systems are usually complex and large in terms of components redundancies, interconnections, interdependency, and support systems. In such hybrid 
systems, some components can interact directly with the physical phenomena while others may not. Therefore, a hybrid approach for reliability assessment can be useful to study the dynamic behavior of the system. Fig.1 exhibits the concept of hybrid reliability assessment approach in which the system consists of interacting subsystems showing probabilistic and deterministic behavior and some probabilistic subsystems may not be repairable.



Fig.1. Hybrid reliability concept for probabilistic and deterministic sub-systems

Because PyCATSHOO lacks an in-built reliability analysis method, this paper introduces a scheme to create a hybrid system reliability models and solve it using a customized PyCATSHOO tool. The hybrid system reliability model formalizes the discrete variables using traditional reliability tools such as RBD and FT analysis and deterministic variables based on physical phenomena involved. Fig.2 shows a flowchart of the iterative procedure to assess the dynamic reliability of large scale nuclear safety systems using the proposed approach. 


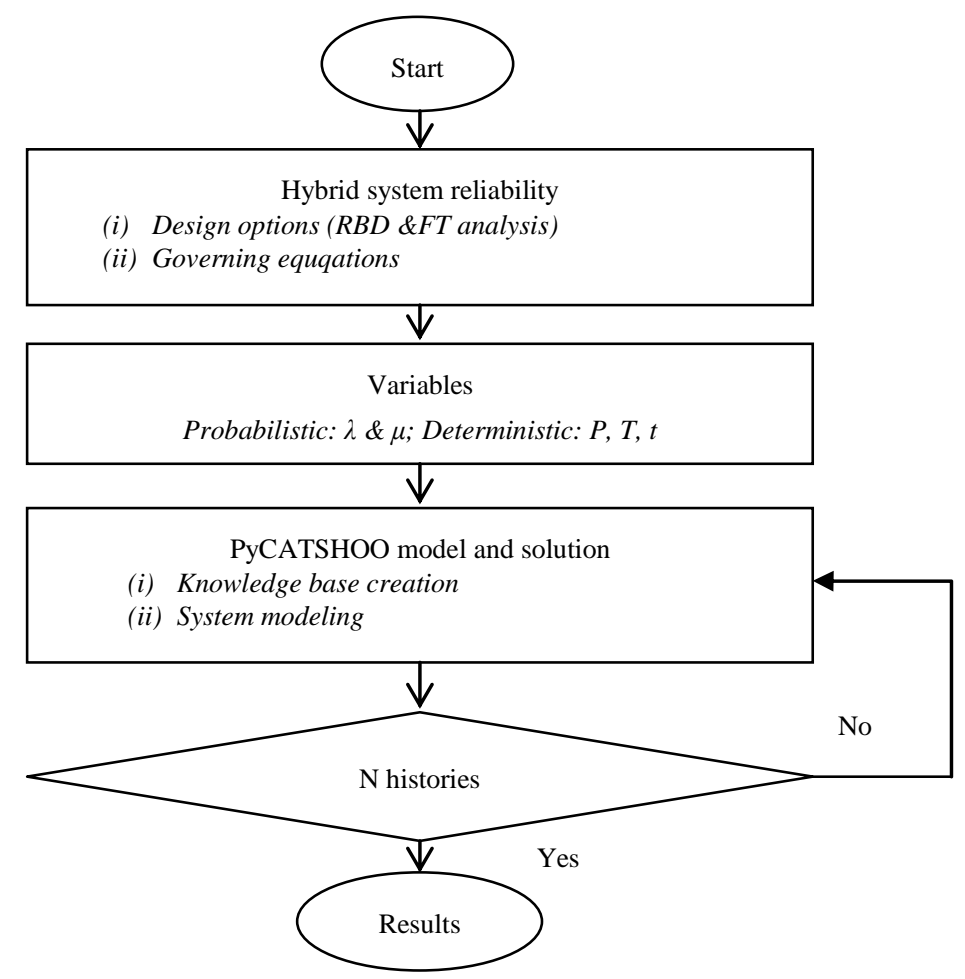

Fig.2. A scheme of dynamic hybrid reliability assessment of large scale systems

The following algorithm depicts the proposed approach:

Step-1: Hybrid system reliability is analyzed using RBD and FT analyses to find out different design options or minimal cut-sets to be studied under dynamic assessment over a mission time.

Step-2: Interacting probabilistic and deterministic variables are identified to feed into stochastic hybrid automata model.

Step-3: The stochastic hybrid automata modeling is done in two sub steps:

Step 3.1: A knowledge base is created by defining several parallel stochastic automata for implementing behavior of system components, a second automaton, termed PDMP controller, to monitor deterministic evolution, if any, 
under this behavior, and message boxes for information exchange among automata and PDMP controller.

Step 3.2: A system model of large system is performed by instantiating the class created in knowledge base and connecting the automata and PDMP controller with message boxes according to architecture of system design under study.

Step-4: The developed model is run for $\mathrm{N}$ - histories and probabilistic and deterministic results are collected for further analysis.

\section{A case study on decay heat removal systems}

For testing the capability of introduced dynamic hybrid reliability approach to achieve the objectives, this paper applies this method to study the safety performance of DHR systems of a Sodium Fast Reactor (SFR). The SFR consists of four DHR systems namely BCS, RRA, RRB, and RRC, as shown in Fig. 3, to remove decay heat generated in the core and transferred through the hot pool $^{30,31}$. In normal conditions, the secondary systems (BCS) transfer the heat from the intermediate heat exchangers (IHX) to the power conversion system.

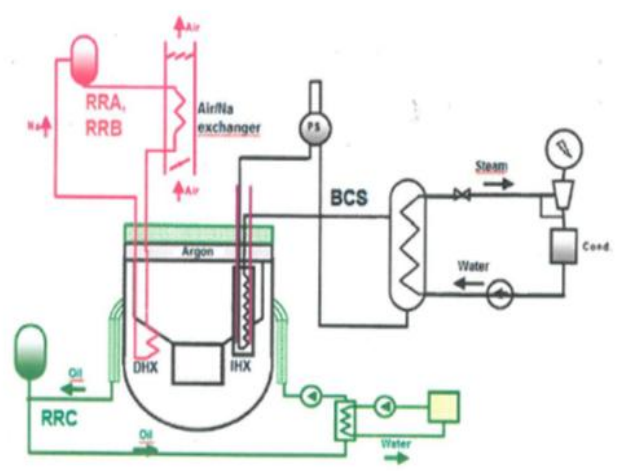

Fig. 3: A schematic diagram of DHR System [31] 
After reactor shutdown, the residual heat can be removed through the secondary loops (BCS) bypassing turbine generator. The use of BCS for residual heat removal is limited to 3 days due to design and operational constraints. When BCS are not available, the decay heat removal relies on dedicated safety system known as RRA, RRB, and RRC (each composed of two redundant trains). Each train of RRA and RRB systems is composed of a Na/Na Decay Heat eXchanger (DHX) and an air/Na exchanger. The two trains of RRB operate in natural convection on both sodium and air sides while RRA trains operate in forced convection with electro-magnetic pumps. Another DHR system, RRC, is also investigated to complement the four DHX circuits.

\subsection{System input data}

This study includes three subsystems of DHR systems namely, RRA, RRB, and RRC for dynamic reliability assessment. The initial operating temperature is $500^{\circ} \mathrm{C}$. DHR systems fail to function if the pool temperature exceeds $650^{\circ} \mathrm{C}$ temperature. Table 1 provides the DHR systems data used in this case studies. The top event failure probabilities of RRA, RRB, RRC have been calculated using RiskSpectrum® PSA tool.

Table 1: DHR systems data

\begin{tabular}{|c|c|c|c|}
\hline & Top event failure probability & Operating time (hr) & Initial state \\
\hline RRA & $3,63-02$ & 100 & ok \\
\hline RRB & $3,12 \mathrm{E}-02$ & 100 & ok \\
\hline RRC & $6,35 \mathrm{E}-03$ & 100 & ok \\
\hline
\end{tabular}




\subsection{Dynamic hybrid reliability analysis}

\subsubsection{Design options}

As an example to test the PyCATSHOO applications, three design options were selected for this study as given in Table 2 below. The effective failure rates have been calculated using RiskSpectrum ${ }^{\circledR}$ PSA tool.

Table 2: RBD analysis and effective failure rate

\begin{tabular}{|l|l|l|l|l|l|}
\hline S. & Combinations & RBD-Physical phenomena & $\begin{array}{l}\text { Effective } \\
\text { failure rate } \\
\text { (100 hrs })\end{array}$ \\
\hline 1 & $\begin{array}{l}2 \text { RRA, 2RRB, } \\
\text { 1RRC } \\
\text { (in Series) }\end{array}$ \\
\hline 2 & $\begin{array}{l}\text { 2 RRA, 2RRB, } \\
\text { (all } \\
\text { parallel) }\end{array}$ \\
\hline 3
\end{tabular}




\subsubsection{Governing equations}

All the three design options interact with pool sodium and sodium temperature evolution is governed by following differential equation:

$$
\begin{gathered}
\mathrm{MC}_{p} \frac{\mathrm{dT}}{\mathrm{dt}}=\mathrm{P}_{D H}(\mathrm{t})-\mathrm{P}_{\text {extracted }} \\
\mathrm{P}_{\text {extracted }}=\mathrm{P}_{R R A} * \mathrm{nRRA}+\mathrm{P}_{R R B} * \mathrm{nRRB}+\mathrm{P}_{R R C} * \mathrm{nRRC}+\mathrm{P}_{\text {leakBCS }} * \mathrm{nBCS} \\
\mathrm{P}_{D H}(\mathrm{t})=0.5+\sum_{\mathrm{i}=1}^{8} \exp (\lambda(\mathrm{i})-\alpha(\mathrm{i}) * \mathrm{t})(\mathrm{MW}, \mathrm{t} \text { in second }) \\
\mathrm{P}_{R R A}=0,028(\mathrm{~T}-93)(\mathrm{MW}) \\
\mathrm{P}_{R R B}=0,025(\mathrm{~T}-122)(\mathrm{MW}) \\
\mathrm{P}_{R R C}=3.10^{-5} \mathrm{~T}^{2}-9.10^{-3} \mathrm{~T}+1,5(\mathrm{MW}) \\
\mathrm{P}_{\text {leakBCS }}=3.10^{-6} \mathrm{~T}^{2}-3.10^{-4} \mathrm{~T}+8(\mathrm{MW})
\end{gathered}
$$

\subsubsection{Stochastic hybrid automata modeling}

\subsubsection{The knowledge base creation}

There are three elements of knowledge base as follows and they are created according to the problem features:

(a) DHR class: Each DHR system is defined by automaton which includes declaration of the state with instruction and creation of the transitions. There are two states/modes of DHR class in this case. The time of occurrence of such failure is random variable which follows exponential distribution.

(b) Message box: Message boxes provide the ability to the instances of such a class to interact with the other system objects. Message box declaration for DHR class got 
two message boxes. In this message box definition, a parameter is invoked when a new value for temperature is received and the results are reset for evaluation of DHR automata transition conditions. This box is used to send information to the POOL class when DHR state is changed.

(c) POOL class: This class models the behavior of the POOL component. Because this class includes physical phenomena with continuous variables, Pool class is modeled by PDMP controller. This PDMP controller will manage a one dimensional state variable vector.

\subsubsection{DHR systems modeling}

The system model is shown in Fig.4. The system is modeled thanks to three instances of the class DHR and to an instance of the class POOL. Through its message box "sensor", the POOL sends current values of mass and temperature which are received by "Sensor" message box of each of the DHR system. In return, through its message box "POOL", a DHR sends the parameter of its current state and the limit of domain where such a state is valid. This message is received by "DHR" message box of the POOL. 


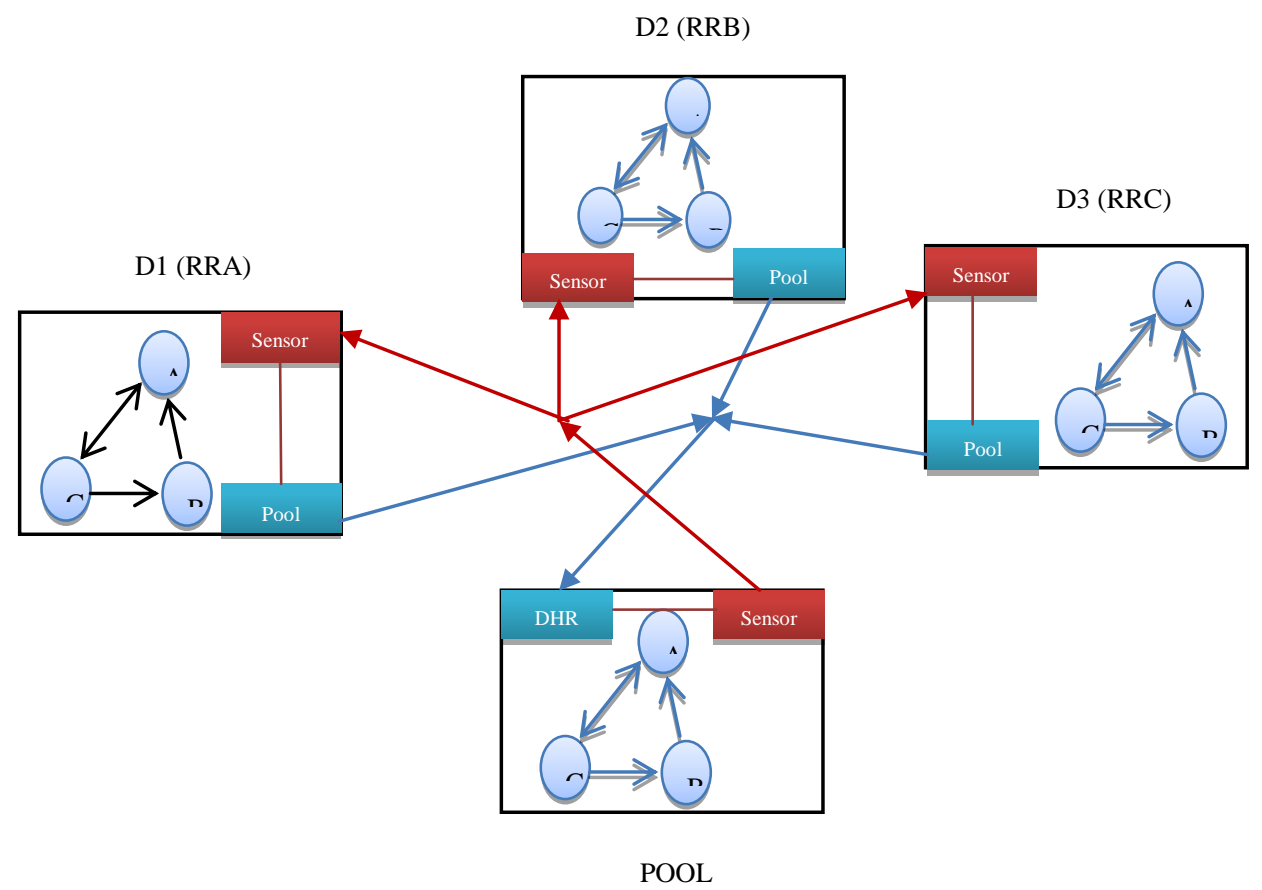

Fig.4: The PyCATSHOO model of the DHR systems

\subsection{Results}

Quantitative results of dynamic reliability assessment of DHR systems using PyCATSHOO are shown in Table 3. Three combinations of those systems as worked out in Table 2 were analyzed for three sets of repair rates. Results include mean, standard deviation, and 95\% confidence interval of the pool temperature for 100 histories during a mission time of 100 hours. 
Table 3: Results with 100 histories

\begin{tabular}{|c|c|c|c|c|c|}
\hline \multirow[b]{2}{*}{ Options } & \multirow[b]{2}{*}{ Design option } & \multirow[b]{2}{*}{ Repair rate } & \multicolumn{3}{|c|}{ Pool temperature $\left({ }^{\circ} \mathrm{C}\right)$} \\
\hline & & & Mean & $\begin{array}{l}\text { Standard } \\
\text { deviation }\end{array}$ & $\begin{array}{c}95 \% \text { confidence } \\
\text { interval }\end{array}$ \\
\hline \multirow[t]{3}{*}{1} & \multirow{3}{*}{$\begin{array}{l}2 \text { RRA, 2RRB, 1RRC } \\
\text { (in Series) }\end{array}$} & 0.99 & 150 & 14 & 147.26 to 152.74 \\
\hline & & 0.10 & 162 & 25 & 157.1 to 166.9 \\
\hline & & 0.000001 & $>1000$ & -- & -- \\
\hline \multirow[t]{3}{*}{2} & \multirow{3}{*}{$\begin{array}{l}2 \mathrm{RRA}, 2 \mathrm{RRB}, 1 \mathrm{RRC} \\
\text { (all are in parallel) }\end{array}$} & 0.99 & 129 & 1 & 128.8 to 129.2 \\
\hline & & 0.1 & 129 & 1 & 128.8 to 129.2 \\
\hline & & 0.000001 & 129 & 1 & 128.8 to 129.2 \\
\hline \multirow[t]{3}{*}{3} & \multirow{3}{*}{$\begin{array}{l}2 \mathrm{RRA}, 2 \mathrm{RRB}, 1 \mathrm{RRC} \\
\text { are operating } \\
\text { independently }\end{array}$} & 0.99 & 150 & 14 & 147.26 to 152.74 \\
\hline & & 0.1 & 161 & 25 & 156.1 to 165.9 \\
\hline & & 0.000001 & $>1000$ & -- & -- \\
\hline
\end{tabular}

The graphical results are shown in Fig.5, Fig.6, and Fig.7 for three sets of repair rate for each design combinations. The $\mathrm{x}$-axis and the $\mathrm{y}$-axis show mission time and Natemperature, respectively. The lines marked in red, green, and blue show the 99\%, mean, and $1 \%$ fractile of the Na-temperature for 100 histories during the mission time of 100 hrs. The 100 histories were taken because of computational limits available in this study. This can be more with higher computational resources.



(a) Repair rate $=0.99$



(b) Repair rate $=0.1$ 




(c) Repair rate $=0.000001$

Fig.5: Pool temperature evolution with 2 RRA, 2RRB, 1RRC (in Series)

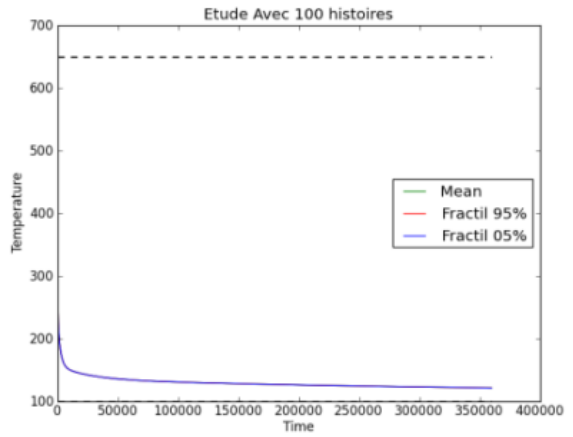

(a) Repair rate $=0.99$

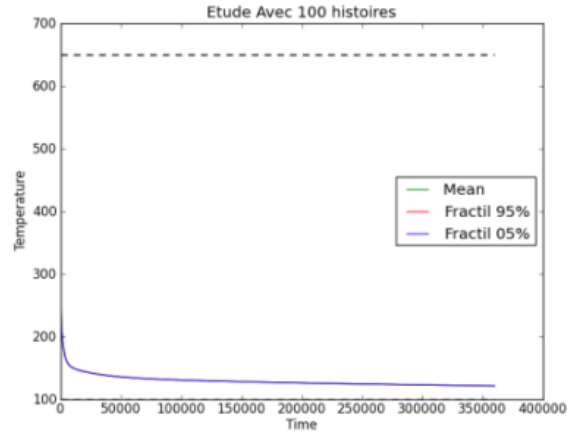

(b) Repair rate $=0.1$



(c)Repair rate $=0.000001$

Fig.6: Pool temperature evolution with 2 RRA, 2RRB, 1RRC (all are in parallel) 


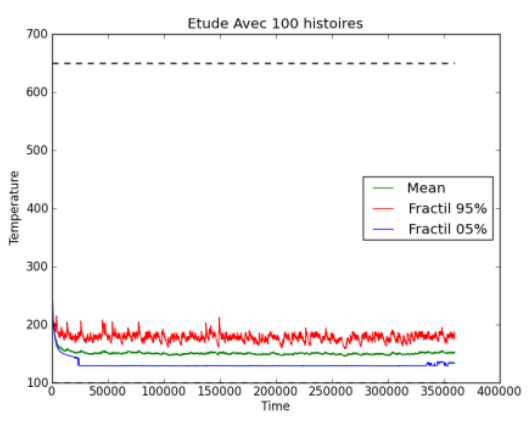

(a) Repair rate $=0.99$

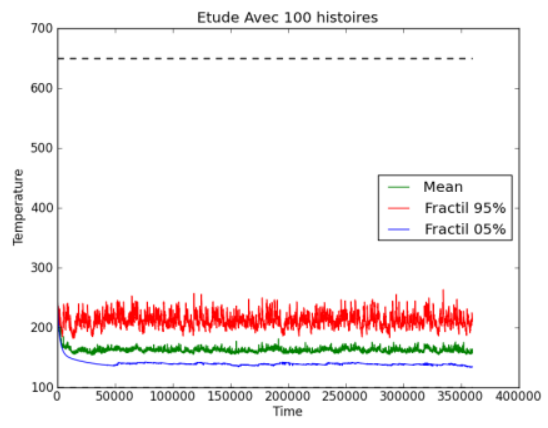

(b) Repair rate $=0.1$

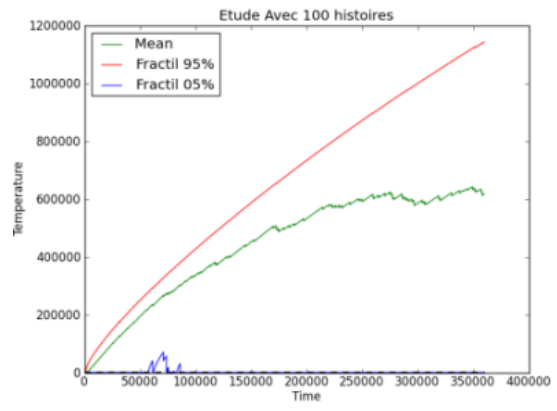

(c) Repair rate $=0.000001$

Fig.7: Pool temperature evolution with 2 RRA, 2RRB, 1RRC are operating independently

\section{Discussion}

The results obtained in Table 3 demonstrate that the proposed scheme of dynamic reliability evaluation of hybrid nuclear systems such as DHR systems provides an insight about its performance during a mission time. The hybrid combination helps to streamline the reliability composition using traditional RBD and FT analysis and dynamic transition using the customized PyCATSHOO. This approach can be applied during design and development stage to assess the performance of a design options with different mission time. This makes possible to correlate the value of probability with the deterministic behavior of the hybrid system. If the system components can be repaired within a grace period, this study enables the analysis of system behavior dynamically. 
The graphical results, as shown in Fig.4, Fig.5, and Fig.6, visualize the temperature evolution with respect to the failure and repair probabilities of each DHR systems combination. It can be observed that the repair possibilities, partial or complete, of the DHR systems enhance its performance to remove the decay heat successfully for a long mission time. The simulation provides the information on $95 \%$, mean, and $1 \%$ fractile of 100 histories during the mission time which provides the uncertainty estimation for the DHR system behavior.

From the results, it can be found that the best combination among the three design options is 2 RRA, 2RRB, 1 RRC in parallel for successful removal of decay heat even without any repair possibility. All the combinations without some repair possibility are not preferable for long mission time. Other combinations and dependency of support systems needs to be investigated for the safest possible systems design.

Though the studies on dynamic reliability evaluation provide an efficient tool to model and simulate large hybrid safety system, the probability density functions of component failure and repair have been assumed exponential for simplification. The customized PyCATSHOO tool allows including user's defined failure and repair law in modeling and simulation. Moreover, the future study on dynamic reliability of DHR systems should include the detailed modeling of DHR components and their dependencies on support systems. This may be done using dependency modeling of reliability theory.

\section{Conclusion}

To capture the dynamic interactions of probabilistic and deterministic variables during a mission time, this paper presents a hybrid scheme of dynamic reliability assessment 
scheme. This hybrid approach includes a combination of conventional reliability compositional analysis tools and the customized Pythonic objects oriented stochastic hybrid automata method. A case study on dynamic reliability studies of decay heat removal systems of a sodium fast reactor is performed using the introduced approach. The results display that repair possibility of some components enhances the overall performance of decay heat removal systems during mission times. The dynamic reliability study results are more explicit than those from the static probabilistic safety assessment methods in mission safety test of decay heat removal systems. In future works, user's defined failure and repair laws with dependencies modeling can be included in similar studies of large scale safety systems.

\section{Acknowledgments}

The authors thank Valentin Rychkov of EDF Clamart in Paris for his technical guidance on PyCATSHOO installation and usage for case studies conducted in this paper.

\section{References}

1. A. K. Nayak, A. Chandrakar and G. Vinod, Frontiers of Energy Research 2:40 (2014), doi:10.3389/fenrg.2014.00040.

2. M. Saez, J.C. Robin, B. Riou, A. Villedieu, D. Deprest and G. Prele, Status of ASTRID nuclear island pre-conceptual design, in Proc. of Front. Res.2013, Paris, 2013, IAEA-CN-199.

3. IAEA-TECDOC-626, Safety related terms for advanced nuclear plants (1991), http://wwwpub.iaea.org/MTCD/publications/PDF/te_626_web.pdf.

4. R. Goebel, R.G. Sanfelice and A. Teel, IEEE Cont. Systems 29:2 (2009), 28-93.

5. M. Bouissou, Stochastic hybrid systems, in 4th IFAC Workshop on Dependable Control of Discrete Systems, Vol.4(1), University of York, 2013. 
6. P. E. Labeau, C. Smidts and S. Swaminathan, Rel. Engineering and System Safety 68 (2000), 219-254.

7. U. S. Nuclear Regulatory Commission, Reactor safety study, an assessment of accident risks in U.S. nuclear power plants, WASH-1400 (1975), http://pbadupws.nrc.gov/docs /ML0706 /ML070610293.pdf.

8. T. Aldemir, Annals of Nuclear Energy 52 (2013), 113-124.

9. C. D. Fetcher and R. R. Schultz, RELAP5/MOD3 User guideline in NUREG/CR-5535 (1992), http://pbadupws.nrc.gov/docs/ML1103/ML110330200.pdf.

10. R. O. Gauntt, R. K. Cole, C. M. Erickson, R. G. Gido, R. D. Gasser, S. B. Rodriguez and M. F. Young, MELCOR computer code manuals in NUREG/CR-6119/SAND 65713 (2005), http://pbadupws.nrc.gov/docs/ML0101/ML010120456.pdf.

11. G. R. Amendola, DYLAM-1, a software package for event sequence and consequence spectrum methodology (Commisssion of European Communities, 1984).

12. S. N. Acosta, Rel. Engineering and Sys. Safety 41 (1993), 135-154.

13. K. S. Hsueh and A. Mosleh, Rel. Engineering and Sys.Safety 52:3(1996), 297-314.

14. M. Kloos and J. Peschke, Nucl. Sc. and Engineering 153(2006), 137-156.

15. U. Catalyurek, B. Rutta, K. Metzrothb, A. Hakobyanb, T. Aldemir, R. Denningb, S. Dunaganc and D. Kunsmanc, Rel. Engineering and Sys. Safety 95(2010), 278-304.

16. M. A. Marsan, G. Balbo, G. Conte, S. Donatelli and G. Franceschinis, Modeling with generalized stochastic Petri Nets (New York: Wiley, 1995).

17. S. Swaminathan and C. Smidts, Rel. Engineering and Sys. Safety 65 (1999), 103-118.

18. T. Matsuoka and M. Kobayashi, Nucl. Sc. and Engineering 98(1988), 64-78.

19. C. J. Garrett, S. B. Guarro and G. E. Apostolakis, IEEE Trans. on Systems, Man and Cybernetics 25:5 (1995), 824-840.

20. M. Bouissou, Boolean Logic Driven Markov Processes: a powerful new formalism for specifying and solving very large Markov models, in Proc. of the 6th Probabilistic Safety Assessment and Management Conference, Puerto Rico, 2002. 
21. M. Marseguerra, E. Zio, J. Devooght and P. E. Labeau, Math. and Comp. in Simulation 47 (1998), 371-382.

22. H. Zhang, F. Dufour, Y. Dutuit and K. Gonzalez, Journal of Risk and Reliability 222:4 (2008), 545-551.

23. G. P. Castaneda, J. F. Aubry and N. Brınzei, Journal of Risk and Reliability 225:1(2011), 2841.

24. G. Babykina, N. Brınzei, J. F. Aubry and G. Deleuze, Modelling a feed-water control system of a steam generator in the framework of the dynamic reliability. Annual Conference of the European Safety and Reliability, Amsterdam, 2013.

25. H. Chraibi, Dynamic reliability modeling and assessment with PyCATSHOO: Application to a test case, PSAM Topical Conference, Tokyo, 2013, pp.14-18.

26. Y. H. Lin, Y. F. Li, Dynamic reliability models for multiple dependent competing degradation processes, in Proceedings of the European Safety and Reliability, Wroclaw, 2014.

27. M. H. A. Davis, Journal of the Royal Statistical Society 46:3 (1984), 353-388.

28. S. Verlinden, G. Deconinck and B. Coupe, Rel. Engineering and Sys. Safety 101:3 (2012), 3547.

29. J. Devooght and C. Smidts, Nuclear Science Engineering 111:3 (1992), 229-240.

30. P. Gauthé, F. Curnier, F. Bertrand, N. Duflot, M. Balmain, V. Richkov and Y. Banchieri, Use of simplified PSA studies in support of the ASTRID design process, in Proc. of Front. Res. 2013, Paris, 2013, IAEA-CN-199/221.

31. F. Curnier, P. Gauthé, P. Quellien, F. Bertrand, H. Gentner, L. Vinçon, S. Jouve, M. Balmain, V. Rychkov and Y. Banchari, Preliminary results from PSA studies to support the ASTRID design process, in Proc. of ICAPP, Charlotte, 2014. 